\title{
Natural Experiment by Definition of the Qualitative Picture of Process of Slipping of the Wheel of the Car Road Laboratory
}

\author{
Zadvornov VY, Kochetkov AV*, Yankovskij LV and Chudinov VA \\ Perm national research polytechnical university, Russia
}

ISSN: 2576-8840

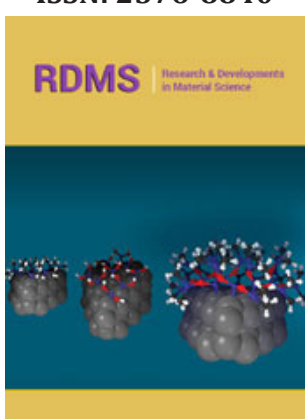

*Corresponding author: Kochetkov AV, Perm national research polytechnical university, Russia

\section{Submission: 䀯 March 25, 2019 \\ Published: 此 April 02, 2019}

Volume 10 - Issue 3

How to cite this article: Zadvornov $\mathrm{V}$, Kochetkov A, Yankovskij L,d Chudinov V. Natural Experiment by Definition of the Qualitative Picture of Process of Slipping of the Wheel of the Car Road Laboratory. Res Dev Material Sci. 10(3).RDMS.000739.2019. DOI: 10.31031/RDMS.2019.10.000739

Copyright@ Kochetkov AV, This article is distributed under the terms of the Creative Commons Attribution 4.0 International License, which permits unrestricted use and redistribution provided that the original author and source are credited.

\begin{abstract}
In this article the natural experiment by definition of qualitative picture of formation of process of slipping of wheel of the car on ice-covered covering and elimination of slipping by means of the dosed adding is considered by coarse-grained frictional material. The algorithm of carrying out experiment has provided satisfactory repeatability of the received values of the studied slipping process parameters. The qualitative picture of process of slipping of wheel of the ice-covered hole which is leading to drop of coefficient of clutch and not allowing to leave to the car has been received. Qualitative and quantitative parameters of doses of coarse-grained frictional material for drop of turns of wheel and departure with the simultaneous termination of process of slipping are determined. For elimination of process of slipping of the car and exit of wheel to steady progress, it is offered to develop mathematical model on the basis of provisions I.P. Rabinovich's theory.
\end{abstract}

Keywords: Slipping of wheel; Clutch coefficient; Frictional material; Condition of the movement of the car; The condensed snow

\section{Mini Review}

During the winter period traffic is at a loss because of deterioration in weather, unexpected snowfalls owing to what the roadbed becomes covered by the wet or condensed snow, and places and ice that involves reduction of clutch of wheel of vehicles with surface of road carpet. This problem is solved various modes, including and by means of various modern deicing materials [1]. But often there are such cases when on roads with setup, there is full fall of wheels to hard road carpet, at the same time due to frosting there is slipping of wheels that results in impossibility of the movement of the car. This problem can annually be observed on roads of our country from October to April. In this regard considerations of slipping of wheel of the car, i.e. definition of qualitative picture of this process - formation of knurled, ice-covered hole is relevant. At the same time interestingly how to liquidate this process. It is known that this case pour frictional material, but how many it needs precisely to be placed in spot of contact piece of wheel to road carpet, for the sure termination of process of slipping depending on weather conditions and technical parameters of wheel? For this purpose, it is necessary to make natural experiment for identification of qualitative picture of process of slipping and perhaps quantitative parameters of doses of frictional material. For the purpose of drop of environmental pressure on the roadside territory it is offered to apply as frictional material coarse-grained-marble crumb or any other same material.

The purpose of natural probe-definition of qualitative picture of formation of process of slipping of wheel of the car on ice-covered covering and elimination of slipping by means of the dosed adding by coarse-grained frictional material.

For achievement of goal it is necessary to solve the following problems:

1. To pick up the equipment, to develop and create conditions and the algorithm of natural experiment providing repeatability of process of slipping of wheel of the car.

2. To define qualitative picture of formation of process of slipping of wheel about formation of the ice-covered hole to hard coating which is leading to drop of coefficient of clutch and not allowing to leave to the car hole. 
3. To define qualitative and quantitative picture of drop of turns of wheel and departure with the simultaneous termination of process of slipping by the dosed adding coarse-grained frictional material.

4. To offer mathematical model for elimination of process of slipping of the car and exit of wheel to steady progress, i.e. what amount of coarse-grained frictional material it is necessary to apply one-time to wheel with various technical parameters.

For carrying out natural experiment the front-wheel Ford Tourneo car with studded wheels and manual gear box has been chosen. The car was placed on the snow-covered knurled flat platform covered with dense snow up to $7 \mathrm{~cm}$ in depth. Temperature:-10 ${ }^{\circ} \mathrm{C}$. Engine speed at which there took place the experiment - $1500 \mathrm{rpm}$. Corner of the experimental platform, 0 hail [2-4].

Preparation of semicircular holes of setup (holes) occurred as follows:

1) The car approached the place of experiment which for safety was protected with road orange cones (Figure 1);

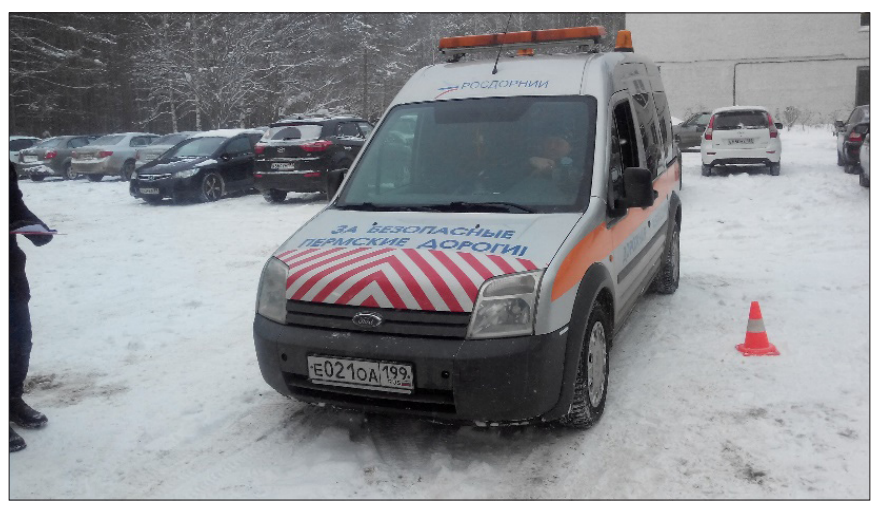

Figure 1: The road laboratory has come out to the venue of experiment..

2) The parking brake turned on;

3) The car engine on the first drive was started;

4) The car stood still, and one of driving wheels of the front bridge began to rotate with the doubled speed as the car differential works;

5) It led to fast milling of semicircular hole to asphalt on the one hand of the car;
6) Further the gear box was turned to neutral position, the engine was not switched off, the car was removed from parking brake;

7) The reverse gear turned on and the car drove off on back on 1-2 meters;

8) Photography and measurement of the received hole (Figure 2) was performed;

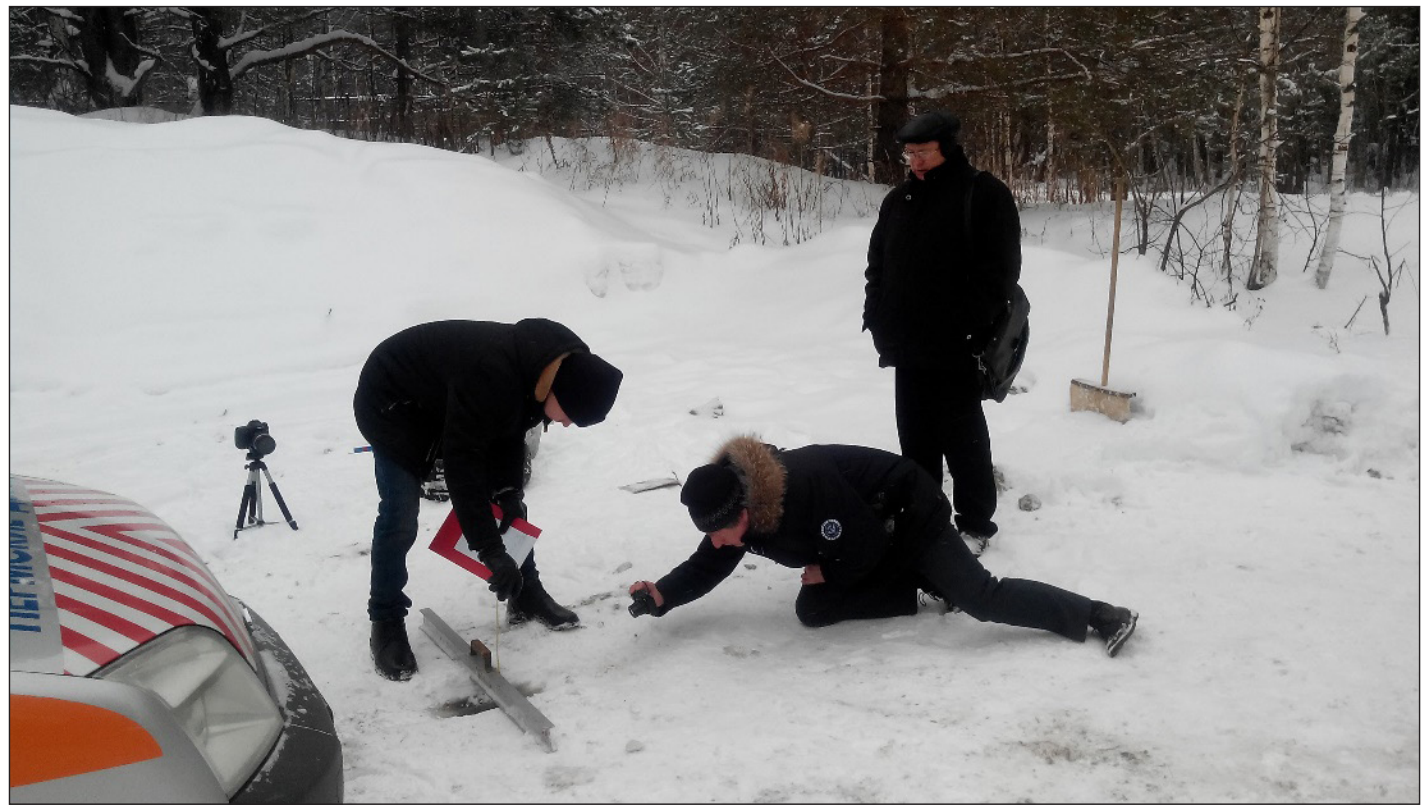

Figure 2: Measurements of the first hole.

9) Then the same hole under the second wheel of the front bridge which did not move (Figure 3) was dug out; 


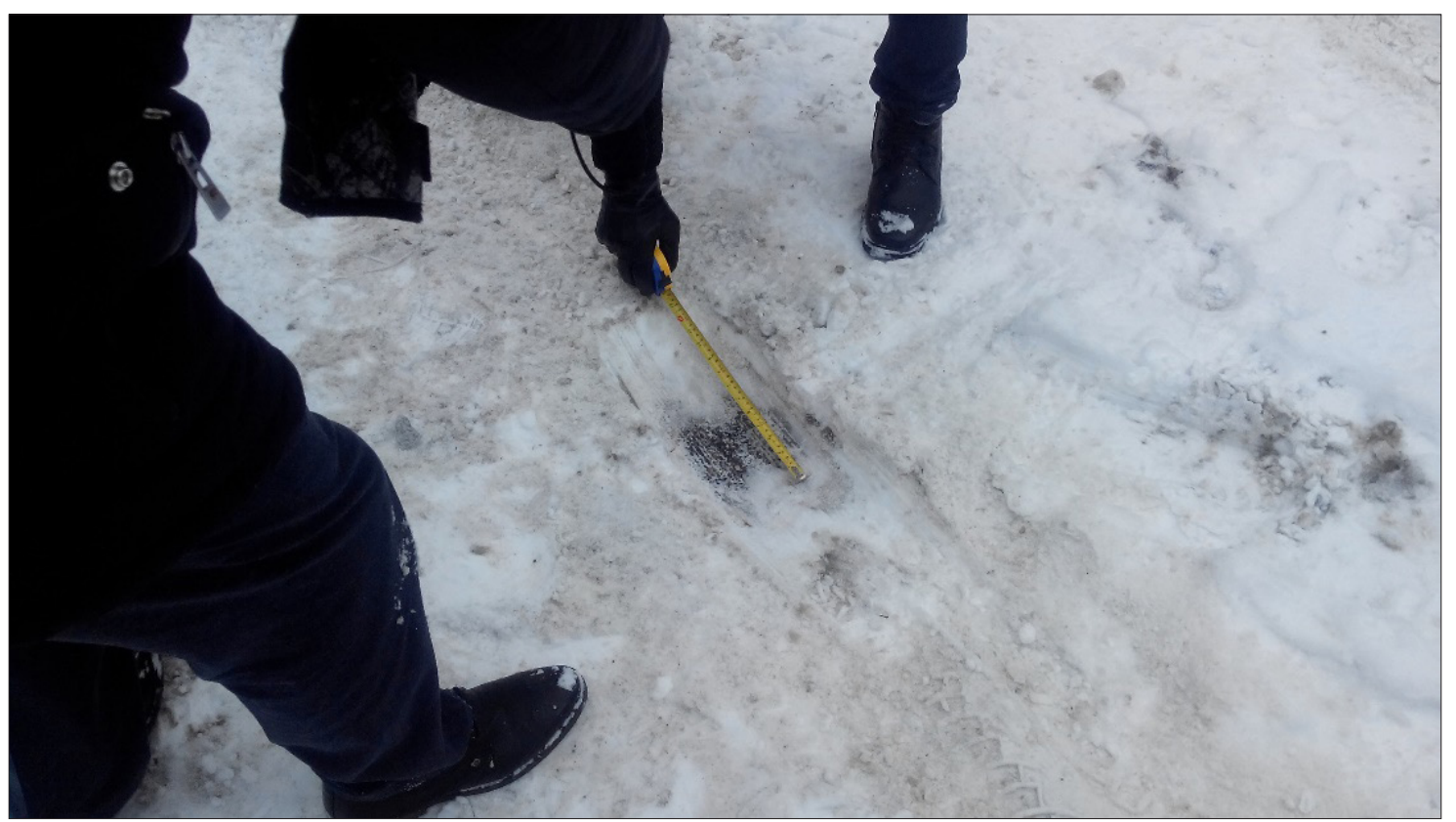

Figure 3: Production and measurements of the second hole.

10) Both holes had full spot of contact piece to asphalt;

11) Then the interior of semicircular holes was spryskivat water;

12) Waited for formation of frost, about 10-15 minutes (Figure 4);

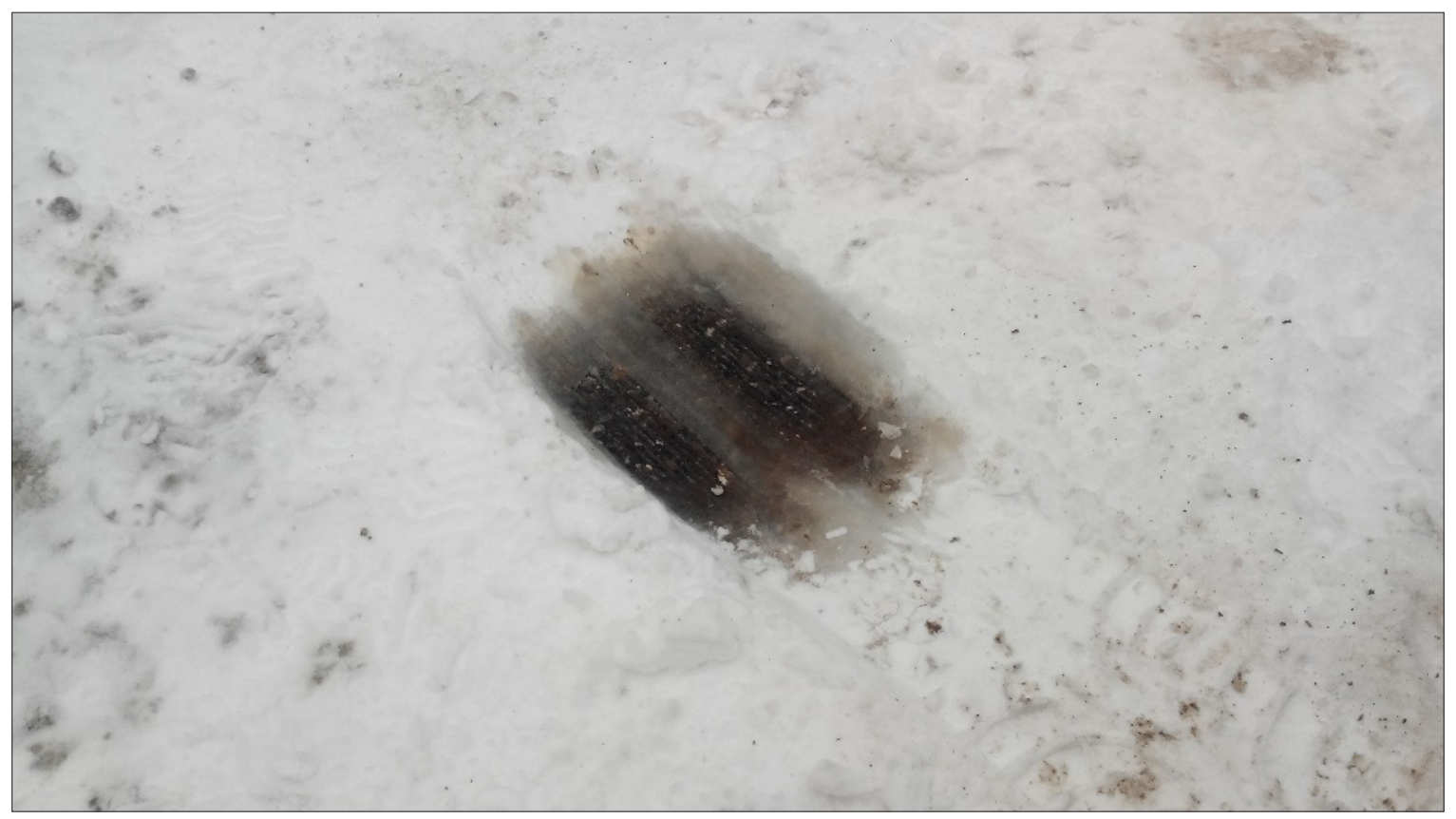

Figure 4: Formation of frost on hole.

13) Then the car slowly ran into these holes and failed in them damping the engine;

Further the experiment was made, at the same time the following picture was observed:

a) The engine turned on the first drive without parking brake, one of wheels rotated with the doubled speed, and another stood in hole, the car could not leave two ice-covered holes though depth was only $6 \mathrm{~cm}$. The car surely stood still.

b) Further damped the engine, before wheels due to slipping the conical area (Figure 5) was formed; 


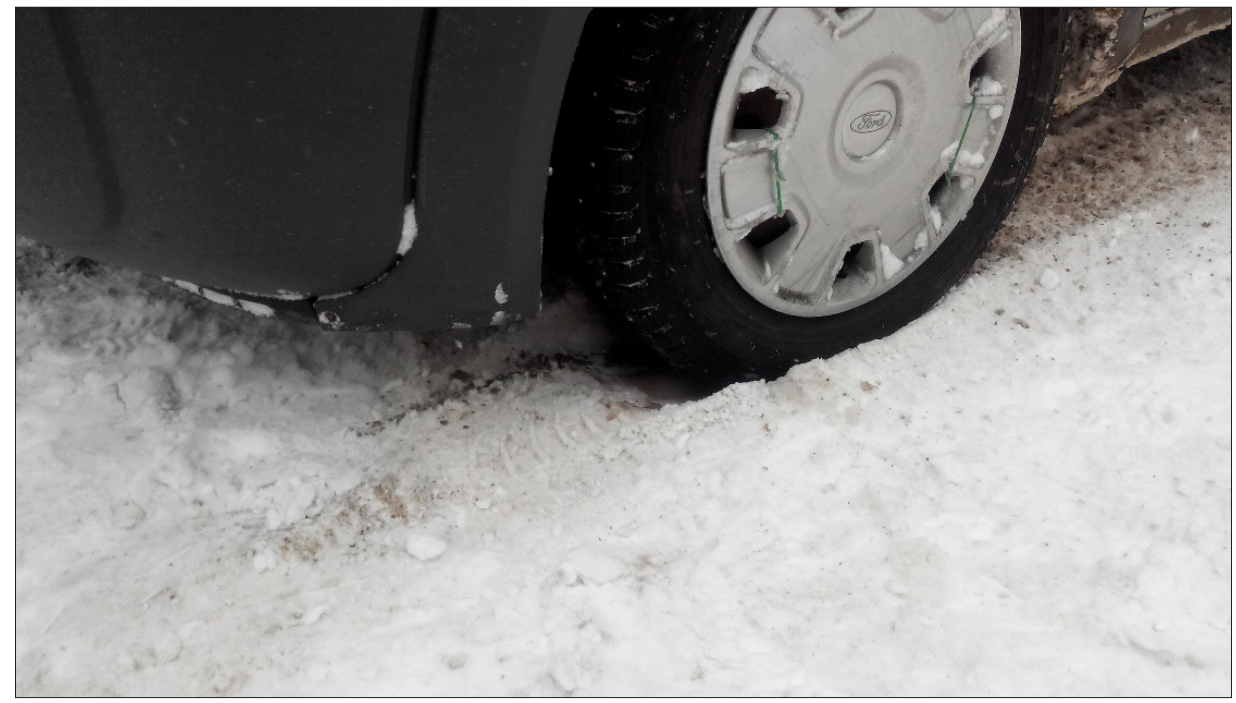

Figure 5: Formation of cone before wheel.

c) To this area under both wheels it is dosed in one portion by scoop (volumetric glass) coarse-grained material (Figure 6) rushed;
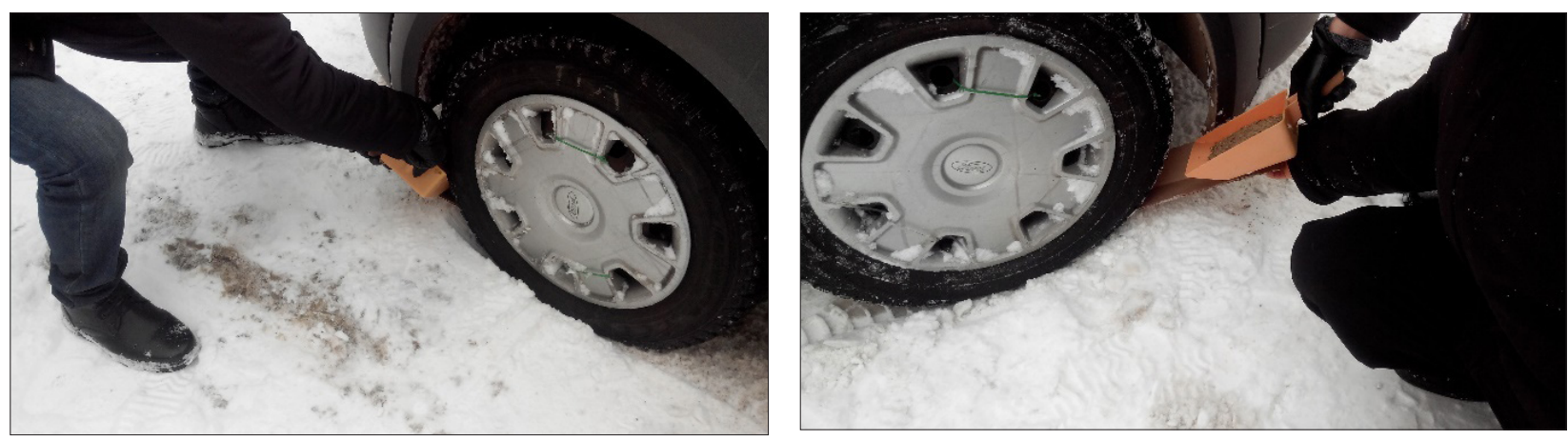

Figure 6: Adding frictional material: a) - left wheel; b) - right wheel.

d) Then the engine turned on, and the driver on the first above); drive tried to move out from the place;

e) The qualitative picture was following - at small dose of material (187g) the wheel rotated doubled speed, all material just departed through contact piece spot back, the car surely continued to slip;

f) After that the car was damped and did all preparation of experiment on other place again (according to the scheme see

g) In final total after several attempts, was it is defined amount of material (387g) at which the car was rolled out from holes at once. And the picture of departure was such-at once without slipping inclusion of both wheels with small speed the car quietly left forward and ice-covered holes. Podsypanny material was not scattered and remained where was подсыпан (Figure 7).
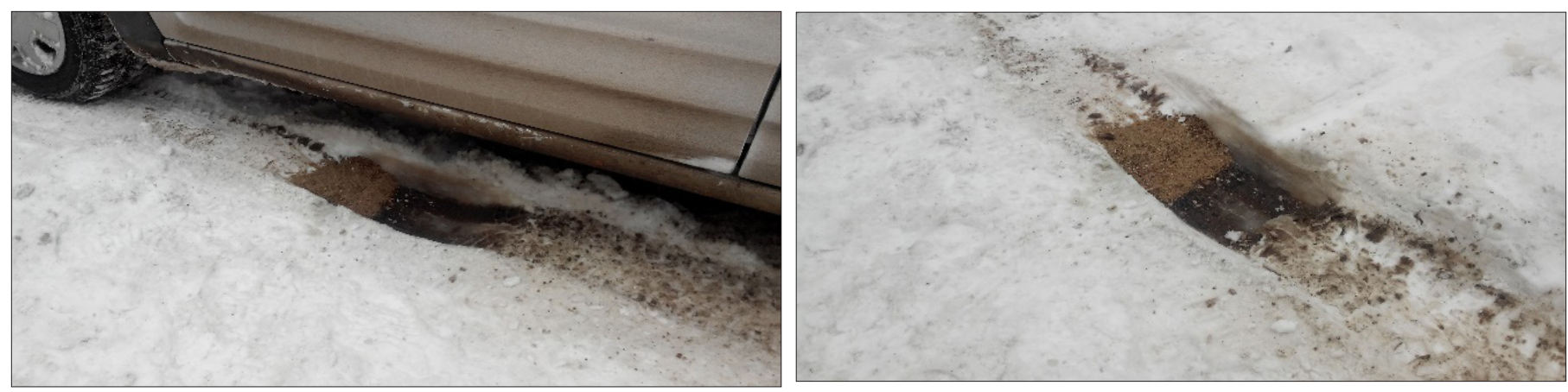

Figure 7: Departure of the car from hole with adding: a) - left hole; b) - right hole. 
Except this main experiment two more which have confirmed the overall qualitative picture of process of slipping and exit from it have been carried out:
1. Slipping deeply $0.15 \mathrm{~m}$. In this case the single dose of $5600 \mathrm{~g}$ of material for the termination of process of slipping (Figure 8) was required.

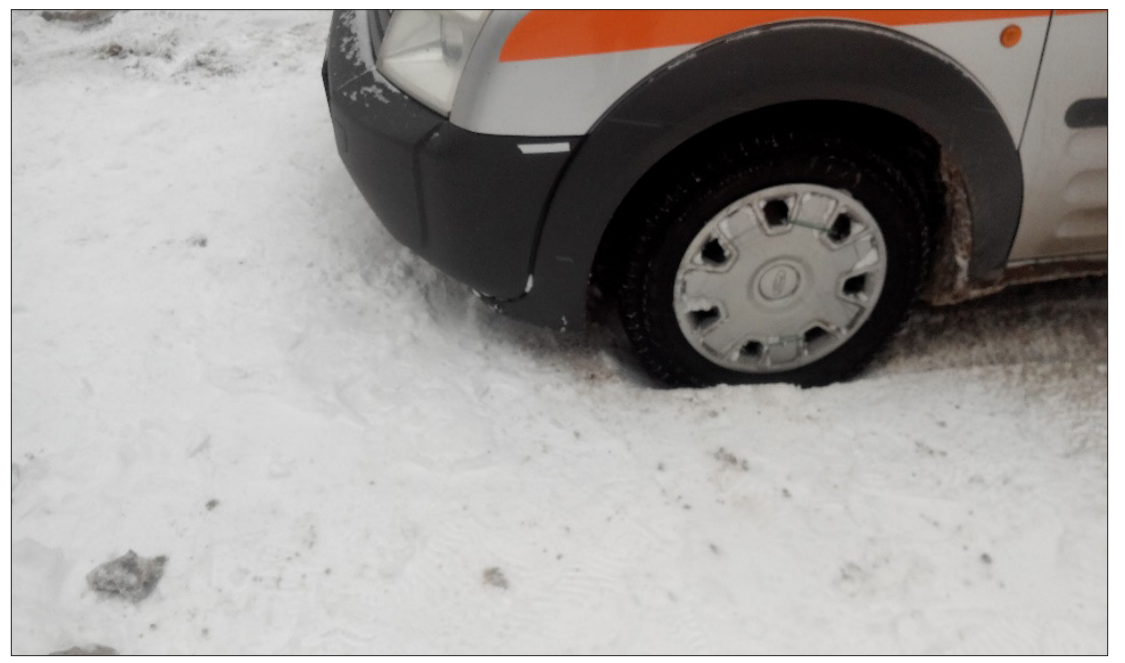

Figure 8: Formation of hole when slipping the car, depth is $0.15 \mathrm{~m}$.

2. Slipping on rise. At the same time holes did not become, and artificial ice-covered rise the $10^{\text {th }}$ hail from which midpoint the movement was made was created. In this case, the single dose of
1120 of material for the termination of process of slipping (Figure 9) was required.

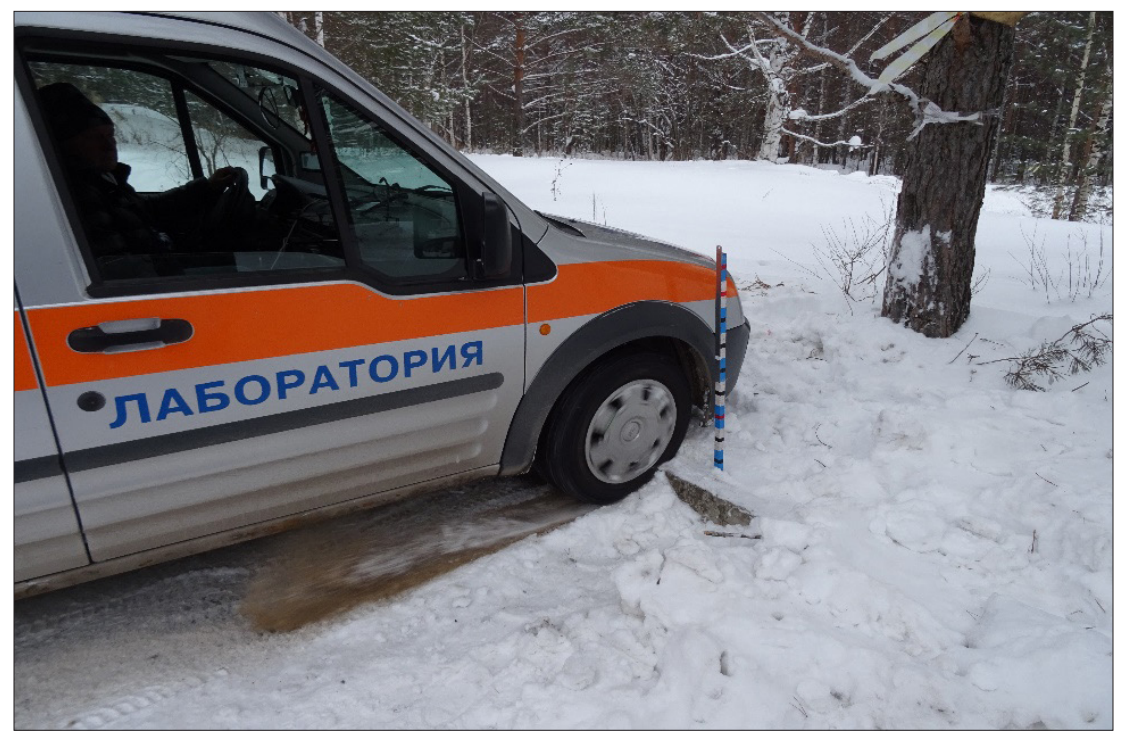

Figure 9: The end of process of arrival on the hill strewed with frictional material.

These natural experiments have shown that swore at podsypaniye of coarse-grained frictional will transform plain surface before wheel during the slipping and zaryvaniye to car snow, to certain similarity of segment area (hill) (Figure 7) thanks to which the car can independently move on the snow-covered area without slipping. This process for off-road cars can be automated by means of the special device of adding the coarse-grained frictional material developed by authors of article.

For calculation of amount of the poured material it is possible to use I.P. Rabinovich's theory, for this process of the movement of the wheel which is bending around segment obstacle [5]. Development of mathematical models of ensuring clutch of wheel with icy road carpet and carrying out numerical experiment (I.P. Rabinovich's model, calculation of risk [6], determination of ranges of interaction and the modes of regulation of system the tire - frictional material road carpet) and also models Balakina [7].

\section{Conclusion}

As a result of the made natural experiment it is possible to draw the following conclusions: 
1. The algorithm of carrying out experiment has provided satisfactory repeatability of the received values of the studied slipping process parameters.

2. The qualitative picture of formation of process of slipping of wheel of the ice-covered hole to hard coating which is leading to drop of coefficient of clutch and not allowing to leave to the car hole has been received.

3. Qualitative and quantitative parameters of doses of coarse-grained frictional material for drop of turns of wheel and departure with the simultaneous termination of process of slipping have been determined.

For elimination of process of slipping of the car and exit of wheel to steady progress, i.e. what amount of coarse-grained frictional material it is necessary to apply one-time to wheel with various technical parameters it is offered to develop mathematical model on the basis of provisions I.P. Rabinovich's theory.

\section{References}

1. Arzhanuhina SP, Garibov RBO, Kochetkov AV, YAnkovskij LV, Gluhov TA, et al. (2013) The choice of requirements for anti-icing materials for the winter maintenance of highways of the megalopolis. Water: chemistry and ecology 4(58): 106-115.
2. Rosavtodor Mintransa RF (2003) ODM Methods of testing anti-icing materials.

3. ODM (2003) A guide to combating winter skidiness on highways. Utverzhdeno rasporyazheniem Mintransa Rossii.

4. Certificate of calibration number SP 1962092 Road diagnostic complex ADK-M-2, based on the Ford car, State Register No. 47309-11, FBU, Rostest-Moscow, Russia.

5. Kokodeeva NE, Kochetkov AV, YAnkovskij LV, Volkov GN (2014) Direct method of calculating the acceleration of the vehicle wheels, taking into account the geometry of the irregularities of the road (method of IP Rabinovich). Truck 3: 17-23.

6. Valiev SHN, Kokodeeva NE, Kochetkov AV, YAnkovskij LV (2016) Simulation of the risk of accidents in taking into account the variability of the macro-roughness of coatings of carriageways on highways and bridges. Construction Materials 5: 22-26.

7. Balakina EV, Kochetkov AV (2017) The coefficient of effective bonding brilliant with the road surface. Innovative engineering, p. 292. 